\title{
SELECTION OF A COMPLEX OF PARAMETERS OF DISTRIBUTION ELECTRIC NETWORKS WITH RESPECT TO TECHNICAL LIMITATIONS
}

\author{
$A D$ Taslimov $^{1}$ \\ ${ }^{1}$ Tashkent state technical university, Department of Power Supply, University street №2, Tashkent, 100095, Uzbekistan
}

\begin{abstract}
The article contains an optimization analysis of the regularities of the formation of the parameters of urban distribution networks of $10 \mathrm{kV}$, taking into account the technical limitations by the method of criteria analysis, which revealed the feasibility of using a limited number of used cable cross-sections, depending on the density of the electrical load and on the schemes of urban distribution networks.
\end{abstract}

\section{Introduction}

Ongoing transformations in the electric power industry of Uzbekistan give particular urgency to the use of a modern approach when justifying the choice of the main parameters of distribution electric networks (RES). In addition, the planned scale of new construction, technical re-equipment and reconstruction of power grid facilities necessitate the development of technical solutions that reflect modern technical and economic realities and meet international standards. At the same time, the low level of implementation of resource and energy saving technologies, the slow pace of renewal of the RES lead to an increase in technological losses and systematic interruptions in the supply of electricity. Analysis of the state of the operating RES showed that $90-92 \%$ of lowvoltage cable lines $6-10-0.38 \mathrm{kV}$ have been in operation for more than 25 years, which requires urgent measures to be taken for further development and formation of a reliable, effective scheme for constructing electrical networks [1-5].

In these conditions, an integrated technical and economic approach to a comprehensive solution to the problems of choosing a set of optimal parameters for a distribution system and the possibility of unifying the lines under construction is especially relevant. At the same time, the determination of the optimal values of the RES parameters should be solved using all the available information and existing mathematical models of network elements, taking into account all the restrictions [6-8]. Optimization of the REM parameters and taking into account a set of restrictions requires the use of a mathematical programming method to solve the problem. This method is a criterion analysis or programming method that allows solving a set of optimization problems. The application of this analysis method makes it possible to identify the optimal network parameters without resorting to a variant calculation. In addition, this method allows for multiparameter optimization taking into account a set of constraints, for which a program for optimizing nonlinear functions with nonlinear constraints using the criterion programming method is used [9-11]. Taking into account the technical and economic models of total capital costs (the cost of cables, electrical installation and construction work), operating costs and electricity losses, a comprehensive technical and economic model of costs for $10 \mathrm{kV}$ RES within one power source (IP) was obtained [7]: $3^{C}=3_{C(1)} \delta^{-0,5} S_{T I I(Y)}^{-0.25} S_{\text {ИI }}^{0.75} M_{C}^{0,5}+3_{(2)} \delta^{-0,5} S_{T I(Y)}^{0,31} S_{\text {HII }}^{0.19} M_{C}^{1,06} F_{2, C}+$ $+3_{C(3)} \delta^{-1,5} S_{T I(Y)}^{-0,88} S_{h I I}^{1,38} M_{C}^{-0,13} F_{2, C} N_{C}^{-1}+3_{C(4)} \delta^{-0,5} S_{T I(Y)}^{0,04} S_{U, T}^{2,46} M_{C}^{-1,21} F^{-1}{ }_{2, C} N_{C}^{0,3}$ This is, $S_{T \Pi(Y)}$ - installed capacity of TS; $\delta$ - electrical load density; $33_{\mathrm{C}(1)}, 3_{\mathrm{C}(2)}, 3_{\mathrm{C}(3)}, 3_{\mathrm{C}(4)}-$ generalized coefficients, which are the initial data [11]:

As a comprehensively optimized parameters, the number of lines from the IP $\left(M_{C}\right)$, section of the head section of 10 $\mathrm{kV}$ lines $\left(F_{2, C}\right)$ and the number of used cable crosssections and $10 \mathrm{kV}\left(N_{F, C}\right)$, according to which "competing effects" are formed in model (1).

Using the criterion analysis method, the model (1) was optimized and formulas were obtained that allow determining the values of the optimized parameters for 10kV RES:

$N_{F, C}^{\ni}=1,405 \cdot 3_{C(1)}^{1,58} \cdot 3_{C(2)}^{-1,553} \cdot 3_{C(3)}^{0,763} \cdot 3_{C(4)}^{-0,79} \cdot S_{T \Pi(Y)}^{-1,579}$,
$F_{2, C}^{\ni}=0,544 \cdot 3_{C(1)}^{1,743} \cdot 3_{C(2)}^{-1,261} \cdot 3_{C(3)}^{-0,112} \cdot 3_{C(4)}^{-0,372} \cdot S_{T \Pi(Y)}^{-0,742}$,
$M_{C}^{\ni}=1,529 \cdot 3_{C(1)}^{-1,327} \cdot 3_{C(2)}^{0,465} \cdot 3_{C(3)}^{0,2} \cdot 3_{C(4)}^{0,664} \cdot S_{\text {ИП }} \cdot S_{T \Pi(Y)}^{0,327}$,

Expressions (2) - (4) allow, with known initial data, to determine the economic values of the main parameters of $10 \mathrm{kV}$ RES.

With the accepted initial data [12-16], the economic values of the parameters determined by (2) $\div$ (4) $N_{F, C} u$ $F_{2, C} M_{c}$ depending on the power of the TP are shown in Fig. 1a, b, c, on which dependencies: "I" - with loop circuits, "II" - with two-beam circuits of networks. 
The obtained economic parameters of $10 \mathrm{kV}$ RES may not satisfy the main technical limitations of $10 \mathrm{kV}$ RES. For $10 \mathrm{kV}$ RES, these are the limitations on heating by current after an emergency mode and on the permissible voltage loss. To solve the above systems of equations, we used a special program developed for solving optimization problems for a nonlinear objective function with nonlinear constraints by the criterion programming
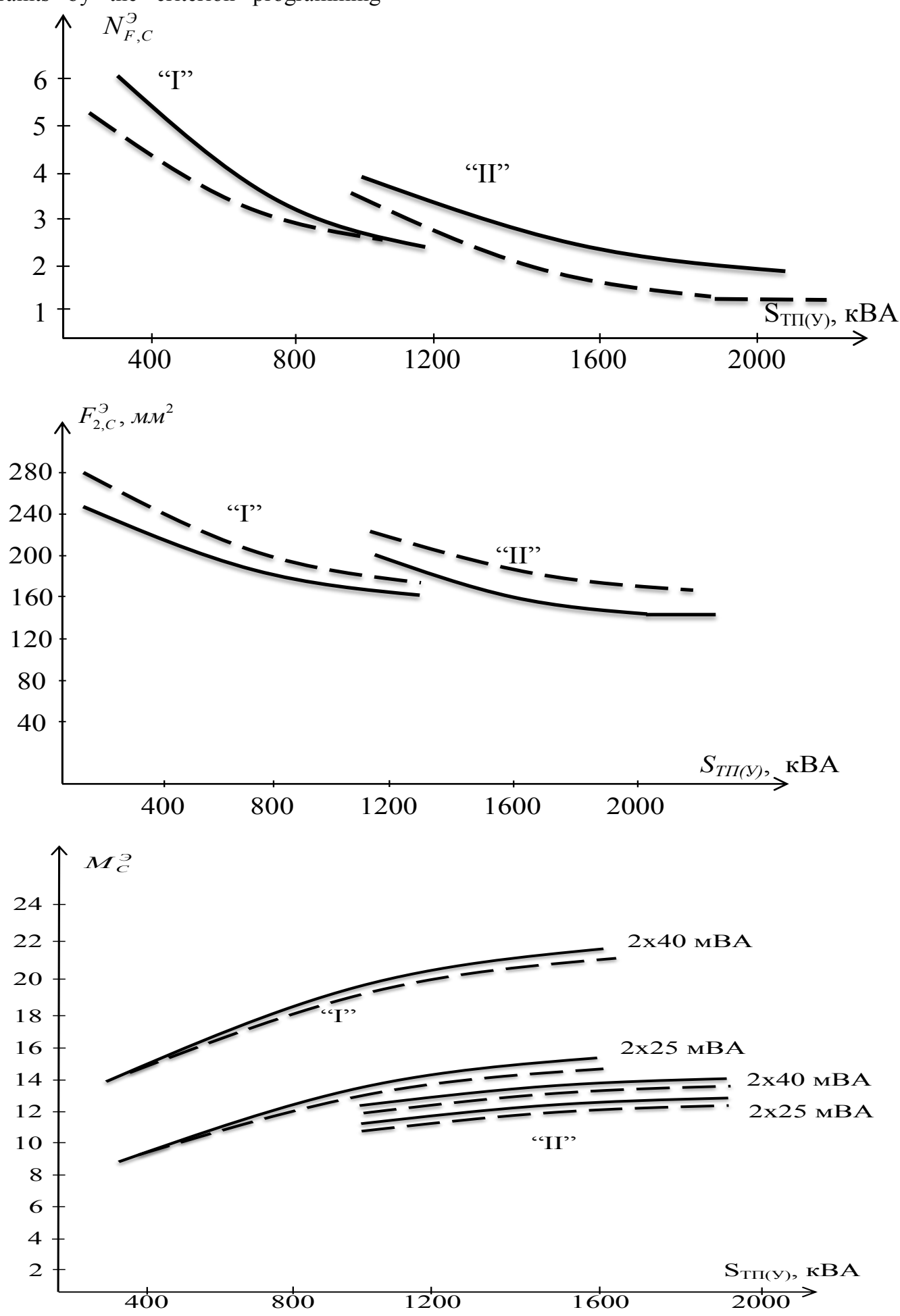

Fig. 1. The values of the number of cross-sections used (a), the cross-sections of the head sections (b) and the number of lines outgoing from the IP (c) RES $10 \mathrm{kV}$ (- - - subject to limitations, — - - no restrictions) method [17-19]. The peculiarity of this program is that it first checks the activity of the considered restrictions, since there are inactive restrictions that lead to a change in the optimized parameters.

The influence of certain active restrictions on parameter values $\mathrm{N}_{\mathrm{F}, \mathrm{C}}, \mathrm{F}_{2, \mathrm{C}}$ and $\mathrm{M}_{\mathrm{C}}$ are shown in Fig. 1a, b, c. 
As the results of optimization of the technical and economic function show, taking into account a set of restrictions, including the limitation on heating $10 \mathrm{kV}$ cables in almost all power ranges of the transformer substation is active, and the limitation on the permissible voltage loss in these networks is inactive. In this case, the conditions are met not by increasing $F_{2 c}$, as is customary in practical design (increasing the cross-section with inadmissibility of heating), but by increasing the number of $10 \mathrm{kV}$ lines leaving the power supply. In this case, the $\mathrm{F}_{2 \mathrm{c}}$ value decreases slightly compared to the value obtained without taking into account the heating limitation. This, in turn, leads to a decrease in the value of $\mathrm{N}_{\mathrm{F}, \mathrm{C}}$ this is especially noticeable at low TP powers (Fig. 1a). It can be assumed that the fulfillment of the condition for the admissibility of heating in the post-emergency mode automatically ensures the admissibility of the voltage loss in these networks [20-23].

Thus, the construction of a $10 \mathrm{kV}$ RES at $S_{T \Pi(y)}=400-1200$ $\mathrm{KVA}\left(\delta<10 \mathrm{MVt} / \mathrm{Km}^{2}\right)$ the optimal is the use of $2 \div 4$ sections and at $S_{T \Pi(y)}=1200-2000 \mathrm{KVA}\left(\delta=10-20 \mathrm{MVt} / \mathrm{Km}^{2}\right)$ it is advisable to use one or two cable cross-sections. In this case, it is recommended to use the sections of the head sections of the lines $240 \mathrm{~mm}^{2}$ or $185 \mathrm{~mm}^{2}$. And at $S_{T \Pi(y)}=2000 \mathrm{\kappa VA}$ and more $\left(\delta=10-20 \mathrm{MVT} / \mathrm{Km}^{2}\right.$ and more $)$ it is advisable to build a $10 \mathrm{kV}$ RES with a single (unified) cable section. In this case, it is recommended to use only the section $150 \mathrm{~mm}^{2}$ [24-29].

\section{Conclusion}

The results obtained by the number and value of the applied cable cross-sections in the RES correspond to similar foreign solutions (France, Russia, Poland, Germany, etc.), which is a certain confirmation of the reliability of the results obtained

\section{References}

1. Koptsev L A, Koptsev A L 2011 Rationing and forecasting of electricity consumption in an industrial enterprise $J$ Industrial power engineering. 1 pp 18-23

2. Hoshimov FA, Rahmonov I U 2014 Rationing of electricity production in the rolling of ferrous metallurgy $J$ European Science review 11-12 pp 56-59

3. Saidkhodjaev A G, Najimova A M and Bijanov A K 2019 Method for determining the maximum load of consumers in city power supply systems E3S Web Conf 139 doi:10.1051/e3sconf/201913901078.

4. Taslimov A D, Rakhmonov I U 2019 Optimization of complex parameters of urban distribution electric networks Journal of Physics: Conference Series 1399 doi:10.1088/1742-6596/1399/5/055046

5. Rakhmonov I U, Niyozov N N 2019 Optimization setting of steel-smelting industry in the issue of alloy steels E3S Web Conf 139 doi:10.1051/e3sconf/201913901077
6. Rakhmonov I U, Reymov K M and Shayumova Z M 2019 The role information in power management tasks. E3S Web Conf 139 doi:10.1051/e3sconf/201913901080 7. Rakhmonov I U, Tovbaev A N, Nematov L A and Alibekova T Sh 2020 Development of forecasted values of specific norms for the issues of produced products in industrial enterprises Journal of Physics: Conference Series 1515 doi:10.1088/1742-6596/1515/2/022050

8. Rakhmonov I U, Nematov L A, Niyozov N N, Reymov K M and Yuldoshev T M 2020 Power consumption management from the positions of the general system theory Journal of Physics: Conference Series 1515 doi:10.1088/1742-6596/1515/2/022054

9. Rakhmonov I U, Reymov K M, Najimova A M, Uzakov B T and Seytmuratov BT 2019 Analysis and calculation of optimum parameters of electric arc furnace Journal of Physics: Conference Series 1399 doi:10.1088/1742-6596/1399/5/055048

10. Taslimov A D, Berdishev A S, Melikuzuev M V and Rakhimov F M 2019 Method of selecting parameters of cable lines distributive networks $10 \mathrm{kv}$ in uncertainty $\begin{array}{llll}\text { conditions } & E 3 S & W e b & \text { Conf }\end{array}$ doi:10.1051/e3sconf/201913901082

11. Taslimov A D, Berdishev A S, Melikuziyev M V and Rakhimov F M 2019 Method of choosing the unification of cable sections of electric network cables under conditions of load development uncertainty E3S Web Conf 139 doi:10.1051/e3sconf/201913901081

12. Rakhmonov, I.U., Berdishev, A.A., Khusanov, B.M., Khaliknazarov, U., Utegenov, U. (2020) General characteristics of networks and features of electricity consumers in rural areas Journal of IOP: Conference Series. MIP: Engineering-2020. 883 (2020) 012104 doi:10.1088/1757-899X/883/1/012104

13. Karimov R.Ch., Shamsiyev K., and others. IOP Conf. Series: Materials Science and Engineering, 883(1), 012142, (2020). doi:10.1088/1757-899X/883/1/012142

14. Karimov R.Ch., Shamsiyeva N. and others. IOP Conf. Series: Materials Science and Engineering, 883(1), 012120, (2020). doi:10.1088/1757-899X/883/1/012120

15.E.G.Usmanov, A.N.Rasulov, M.K.Bobojanov, R.Ch.Karimov. E3S Web of Conferences 139, 01079 (2019), doi.org/10.1051/e3sconf/201913901079

16. Bobojanov M.K., Rasulov A.N., Karimov R.Ch., Sattarov H.A. Bulletin Descendants of Mohammed AlKhwarizmi (ISSN: 2181-9211), Tashkent, 3(5), - PP.106109, (2018).

17. Burievich, T.J. The questions of the dynamics of drilling bit on the surface of well bottom// Arch. Min. Sci. -Poland. - Vol. 61 (2016). - №2. - P. 279-287. DOI 10.1515/amsc-2016-0020.

18. Toshniyozov, L.G., Toshov, J.B. Theoretical and experimental research into process of packing in drilling// Mining Informational and Analytical Bulletin Volume 2019, Issue 11, 2019, Pages 139-151. DOI: 10.25018/0236-1493-2019-11-0-139-151.

19. Avezova N.R., Toshov J.B., Dalmuradova N.N., Farmonova A.A., Mardonova M.Sh.Renewable Energy: Scenario and Model of Development // ISSN 0003-701X, Applied Solar Energy, 2019, Vol. 55, No. 6, pp. 438-445. DOI: 10.3103/S0003701X19060021 
20. Mannanov U., Toshov J., Toshniyozov L. Perspective Solutions for the Design of Drilling Tools / E3S Web of Conferences 105, 03027 (2019) IVth International Innovative Mining Symposium, https://doi.org/10.1051/e3sconf/201910503027

21. Toshov J., Saitov E. Portable autonomous solar power plant for individual use / E3S Web Conf., Volume 139, 01087, 2019, Rudenko International Conference "Methodological problems in reliability study of large energy systems" (RSES 2019), https://doi.org/10.1051/e3sconf/201913901087

22. Azamatovich, A.N., Amrillo, M.B, Burievich, T.J., Umarxanoxich, J.R., Shavkatovich, Z.A. A complex of methods for analyzing the working fluid of a hydrostatic power plant for hydraulic mining machines / International Journal of Advanced Science and Technology. Volume 29, Issue 5 Special Issue, 28 March 2020, Pages 852-855

23. Hoshimov, F.A., Bakhadirov, I.I., Erejepov, M., Djumamuratov, B. (2019) Development of method for normalizing electricity consumption E3S Web Conf 139 doi:10.1051/e3sconf/201913901074

24. Allayev, K.R., Fedorenko, G.M.,Postnikov, V.I.,Ostapchuk, L.B. Asynchronous generators as power system's natural dampers. 43rd International Conference on Large High Voltage Electric Systems 2010, CIGRE 20102010, 9p43rd International Conference on Large High Voltage Electric Systems 2010, CIGRE 2010; Paris; France; 22 August 2010.

25.Fazylov, Kh.F.,Allaev, K.R. Analysis of the operation of an electrical system during simultaneous operation of synchronous and asynchronous generators. Power engineering New York Volume 18, Issue 3, 1980, Pages 81-88.

26.Fazylov, Kh.F.,Allaev, K.R. Asynchronous turbogenerators with stator excitation and the prospects for their utilization. Power engineering New York Volume 23, Issue 2, 1985, Pages 7-13.

27.Fazylov, Kh.F.,Allaev, K.R. Calculation and experimental analysis of conditions of electrical power systems containing induction generators Power Engineering New York Volume 27, Issue 6, 1989, Pages 27-34.

28.Allaev K., Makhmudov T. Research of small oscillations of electrical power systems using the technology of embedding systems. Electrical Engineering, 2020; Issue 1: 309-319.DOI 10.1007/s00202-019-00876-9

29.Allaev K., Makhmudov T. Prospects of diversification and ensuring energy safety of Uzbekistan. E3S Web Conf., Volume 139, 2019, Rudenko International Conference "Methodological problems in reliability study of large energy systems" (RSES 2019).https://doi.org/10.1051/e3sconf/201913901002 